\title{
Treatment outcome and prognostic factor analysis in transplant-eligible Chinese myeloma patients receiving bortezomib-based induction regimens including the staged approach, PAD or VTD
}

\author{
Chor Sang Chim ${ }^{1 *}$, Albert Kwok Wai Lie ${ }^{1}$, Eric Yuk Tat Chan ${ }^{2}$, Herman Sung Yu Liü ${ }^{3}$ Ching Wa Lau ${ }^{4}$, Sze Fai Yip ${ }^{4}$, \\ Joycelyn Sim ${ }^{5}$, Thomas Shek-Kong Wan², Edmond Shiu-Kwan Ma ${ }^{6}$, Raymond Liang ${ }^{1}$, Eric Tse ${ }^{1}$ and \\ Yok-Lam Kwong ${ }^{1}$ for Hong Kong Society of Myeloma ${ }^{1}$
}

\begin{abstract}
Background: We have reported promising outcomes using a staged approach, in which bortezomib/thalidomide/ dexamethasone was used only in 14 patients with suboptimal response to VAD (vincristine/adriamycin/ dexamethasone) before autologous stem cell transplantation (ASCT). Here we compared the outcomes of the staged approach with frontline PAD (bortezomib/doxorubicin/dexamethasone) or VTD (bortezomib/thalidomide/ dexamethasone) induction, and analysed prognostic factors for outcome.
\end{abstract}

Patients and methods: Ninety-one transplant-eligible Chinese patients received three induction regimens prior to ASCT [staged approach $(N=25)$, PAD $(N=31), \operatorname{VTD}(N=35)$ ]. and received thalidomide maintenance for 2 years post-ASCT.

Results: 43 (47.3\%) patients had International Staging System (ISS) III disease. By an intention-to-treat analysis, the overall CR/nCR rate were $37.4 \%$ post-induction, and $62.6 \%$ post-ASCT. Five-year overall (OS) and event-free (EFS) survivals were $66 \%$ and $45.1 \%$. There was no difference of the post-induction CR/nCR rate, EFS or OS between patients induced by these three regimens. Moreover, ISS III disease did not affect CR/nCR rates. Multivariate analysis showed that ISS and post-ASCT CR/nCR impacted OS while ISS and post-induction CR/nCR impacted EFS.

Conclusions: These three induction regimens produced comparable and favorable outcomes in myeloma. The unfavorable outcome of ISS stage III persisted despite upfront/early use of bortezomib. CR/nCR predicted favorable survivals.

Keywords: Myeloma, Staged approach, PAD, VTD, Prognostic factors, Deep vein thrombosis

\section{Background}

Bortezomib, a proteasome inhibitor, is an active agent for the treatment of myeloma. Its efficacy was initially demonstrated in the salvage treatment of refractory myeloma patients, with a complete response (CR) rate of 9\% $[1,2]$. Subsequently, a high $\mathrm{CR}$ rate has also been

\footnotetext{
* Correspondence: jcschim@hku.hk

'Department of Medicine, Queen Mary Hospital, University of Hong Kong, Hong Kong, Hong Kong

Full list of author information is available at the end of the article
}

shown with the use of bortezomib-based regimens as induction therapy for newly diagnosed myeloma patients [3]. A post-induction CR rate of $43 \%$ and $30 \%$ was observed when bortezomib-based induction regimens were used in both transplant-eligible and transplantineligible myeloma patients $[4,5]$.

In Hong Kong, we have adopted a staged approach, in which newly diagnosed, transplant-eligible myeloma patients are risk-stratified according to their initial chemosensitivity. Patients who respond to vincristine, 
adriamycin and dexamethasone (VAD) undergo autologous stem cell transplantation (ASCT). Patients who do not respond optimally to VAD receive salvage therapy with bortezomib/thalidomide/dexamethasone (VTD) before ASCT. This staged approach aims at employing early bortezomib-based therapy in patients who do not achieve a rapid cytoreduction after VAD, thereby restricting the use of the expensive bortezomib to patients with suboptimal response to conventional treatment while ensuring "early" bortezomib-based induction therapy. With this strategy, a CR rate of $48 \%$ (by an intention-to-treat analysis), and a 3 -year overall survival of $75 \%$, has been achieved [6]. Based on this approach, we showed that only $56 \%$ myeloma patients required salvage therapy with VTD. During the same study period, two other bortezomib-containing regimens VTD and PAD (bortezomib, doxorubicin, dexamethasone) were also used as first-line treatment of myeloma patients.

In this report, we examined the hypothesis that myeloma patients treated by the staged approach, in which early bortezomib-based induction is used in selected patients, might achieve similar outcomes as compared with patients receiving receiving frontline bortezomibbased regimens.

\section{Patients and methods}

\section{Patients}

Ninety-one newly diagnosed, symptomatic, transplanteligible myeloma patients with measurable disease were studied. Patients who were financially competent received frontline therapy with bortezomib-containing regimens. Other patients received a staged approach, and were treated with bortezomib supported by philanthropy only when the initial response was suboptimal.

\section{Regimens}

\section{Staged approach}

Twenty-five patients received initial cytoreduction with three cycles of VAD (vincristine, adriamycin and dexamethasone). (Figure 1) Those achieving $\geq 75 \%$ reduction in paraprotein proceeded to ASCT $(\mathrm{N}=11 ; 44 \%)$. Patients with $<75 \%$ reduction in paraprotein received salvage therapy with four cycles of VTD (bortezomib: $1.3 \mathrm{mg} / \mathrm{m}^{2} /$ day intravenously on days $1,4,8$ and 11 ; thalidomide: $200 \mathrm{mg} /$ day; dexamethasone: $40 \mathrm{mg} / \mathrm{d}$ orally from days 1-4 and days 8-11), and then ASCT $(\mathrm{N}=14 ; 56 \%)$. All patients received thalidomide (50$100 \mathrm{mg} /$ day) as maintenance therapy post-ASCT.

\section{Bortezomib-containing regimens}

During the same period, 66 patients received 4 cycles of bortezomib-containing regimens (PAD, $\mathrm{N}=31$; and VTD, $\mathrm{N}=35$ ) followed by ASCT. Patients receiving PAD had four 3-weekly cycles of chemotherapy



Figure 1 Staged Approach.

comprising bortezomib $1.3 \mathrm{mg} / \mathrm{m}^{2} /$ dose on days $1,4,8$ and 11 , adriamycin $9 \mathrm{mg} / \mathrm{m}^{2} / \mathrm{d}$ on days $1-4$ and dexamethasone $20 \mathrm{mg} / \mathrm{d}$ days $1-4$, and days $8-11$. Patients receiving VTD had four 3-weekly cycles of chemotherapy comprising bortezomib $1.3 \mathrm{mg} / \mathrm{m}^{2} /$ dose on days 1 , 4, 8 and 11 , thalidomide $200 \mathrm{mg} / \mathrm{d}$, and dexamethasone $20 \mathrm{mg} / \mathrm{d}$ days $1-4$, and days $8-11$. All patients received maintenance thalidomide (50-100 $\mathrm{mg} /$ day) for 2 years post-ASCT.

\section{Stem cell mobilization and conditioning}

Stem cells were mobilized with cyclophosphamide ( $3 \mathrm{~g} / \mathrm{m}^{2}$ intravenously) and granulocyte-colony stimulating factor (300 microgram/day subcutaneously until leucocyte recovery). At least $4 \times 10^{6} \mathrm{CD} 34+$ cells/Kg recipient body weight were collected. ASCT conditioning regimen comprised intravenous melphalan $200 \mathrm{mg} / \mathrm{m}^{2}$.

\section{Staging and laboratory investigations}

Myeloma work-up included bone marrow examination, skeletal survey, serum $\beta_{2}$-microglobulin $\left(\beta_{2} \mathrm{M}\right)$ level, serum protein electrophoresis (SPE), urine protein electrophoresis (UPE), serum or urine immunofixation, paraprotein level assay and serum free light chain (FLC) assay (Freelite, The Binding Site, Birmingham, UK) [7].

\section{Fluorescence in-situ hybridization (FISH)}

Detection of cytogenetic aberrations was performed on myeloma cells in the bone marrow sample by FISH. Enrichment for myeloma cells was achieved by sorting with CD138 immunomagnetic beads (MiniMACS, Miltenyi Biotec, Auburn, CA) if the percentage of myeloma cells were below $50 \%$ of all nucleated cells after haematopathology review. The FISH probes (Abbott Molecular, Abbott Park, IL) comprised the IGH/FGFR3 dual colour dual fusion translocation probe for detection of $t(4 ; 14)$ (p16;q32), the IGH/MAF dual colour dual fusion translocation probe for detection of $\mathrm{t}(14 ; 16)(\mathrm{q} 32 ; \mathrm{q} 23)$ and 
TP53/CEP17 dual colour probe for the detection of p53 deletion, in accordance with the International Myeloma Workshop Consensus recommendation. At least 200 nuclei were analyzed and scored independently by two persons. The cutoff for positivity was above $5 \%$ or at least 10 positive nuclei based on test validation data. Highrisk (HR) karyotypes include $t(4 ; 14), t(14 ; 16)$ or $\operatorname{del}(17 p)$.

\section{Response criteria}

All patients were analyzed on an intention-to-treat basis. Bone marrow plasmacytosis and paraprotein levels were assessed prior to treatment, after VAD, after VTD, and 3 and 6 months after ASCT. Responses were defined according to standard criteria [8]. Complete remission (CR) was defined as complete resolution of disease with absent paraprotein, as evidenced by a negative SPE and immunofixation, and $<5 \%$ plasma cells in the bone marrow. Near-complete remission (nCR) was defined as a negative SPE but positive immunofixation. Partial response (PR) was subclassified into very good partial remission (VGPR, paraprotein reduction $>90 \%$ ), and PR (paraprotein $>50 \%$ reduction). Minor response (MR) was defined as paraprotein reduction of $>25 \%$ but $<50 \%$. No response (NR) was defined as paraprotein reduction of $<25 \%$. Progression was defined as $>25 \%$ paraprotein increase in two consecutive tests four weeks apart. Relapse was defined as reappearance of the paraprotein on immunofixation in CR patients, positive SPE in the nCR patients, and/or appearance of new bone lesions. For patients with light chain myeloma, CR was defined as normalization of the level and ratio of serum FLC, and negative serum and urine immunofixation.

\section{Statistical analysis}

OS was defined as time from commencement of induction therapy to death or last follow-up. Event-free survival (EFS) was defined as time from commencement of induction therapy to the date of progression, relapse or death. Patients were clinically staged according to the international staging system (ISS) [9]. Survival curves were plotted by Kaplan-Meier method and compared by the log-rank test. The association of diagnostic clinical parameters (ISS) and treatment response (post-induction $\mathrm{CR} / \mathrm{nCR}$ or $\geq \mathrm{VGPR}$, and post-ASCT $\mathrm{CR} / \mathrm{nCR}$ and $\geq$ VGPR) with categorical variables including gender, ISS stage, immunoglobulin isotype, post-induction $\mathrm{CR} /$ VGPR or post-ASCT CR/VGPR was studied by ChiSquare test, and age by Student's t-test. Multivariate Cox regression analysis was performed to analyze the impact on OS and EFS of risk factors including pre-treatment clinical characteristics including age, gender, ISS, isotype, and post-treatment responses (post-induction $\mathrm{CR} / \mathrm{nCR}$ and $\geq$ VGPR, or post-ASCT CR/nCR and $\geq$ VGPR) using Statistical Package for the Social Sciences (SPSS) version
16.0. Data on high-risk karyotype was only available in 27 patients, and hence not included in the multivariate analysis. All p-values were two-sided.

\section{Results}

\section{Patients}

There were 50 (54.9\%) men and 41 (45.1\%) women with a median age of 55 years (range: 33-65 years). Apart from one patient with insufficient data, there were 29 (32.3\%) patients with International Staging System (ISS) stage I, 18 (20\%) stage II and 43 (47.7\%) stage III disease. There were 40 (44\%) IgG, 25 (27.5\%) light chain, 15 (16.5\%) IgA, seven (7.7\%) IgD and four (4.4\%) nonsecretary myeloma cases. Of the 27 patients with karyotypic data, high-risk karyotype occurred in nine (33.3\%) [del(17p) in seven and $t(4 ; 14)$ in two]. The demographics and clinical characteristics of patients receiving the staged approach, PAD and VTD were outlined in Table 1. There was no difference in the mean age, and the distribution of gender, ISS, isotype or high-risk karyotypes between these three regimens, thereby permitting a valid comparison of treatment outcomes.

Table 1 Patient demographics and treatment outcomes by regimen

\begin{tabular}{|c|c|c|c|c|}
\hline & $\begin{array}{l}\text { Staged } \\
\text { Approach } \\
\mathrm{N}=25\end{array}$ & $\begin{array}{l}\text { PAD } \\
\mathrm{N}=31\end{array}$ & $\begin{array}{l}\text { VTD } \\
\mathrm{N}=35\end{array}$ & p-value \\
\hline \multicolumn{5}{|l|}{ (A) Demographics } \\
\hline Mean age & 52.44 & 53.42 & 55.71 & 0.18 \\
\hline Male gender & $17(68 \%)$ & 15 (48.4 \%) & $18(51.4 \%)$ & 0.296 \\
\hline Isotype & & & & 0.504 \\
\hline G & 12 & 15 & 13 & \\
\hline L & 6 & 8 & 11 & \\
\hline A & 4 & 2 & 9 & \\
\hline D & 2 & 4 & 1 & \\
\hline NS & 1 & 2 & 1 & \\
\hline ISS & & & & 0.83 \\
\hline 1 & $7(28 \%)$ & 11 (35.5\%) & $11(32.4 \%)$ & \\
\hline$\|$ & $7(28 \%)$ & $5(16.1 \%)$ & $6(17.6 \%)$ & \\
\hline III & $11(44 \%)$ & 14 (48.4\%) & $17(50 \%)$ & \\
\hline High-risk Karyotype & $3 / 5(60 \%)$ & 2/6 (33.3\%) & $4 / 12(25 \%)$ & 0.35 \\
\hline \multicolumn{5}{|l|}{ (B) Outcomes } \\
\hline $\begin{array}{l}\mathrm{CR} / \mathrm{nCR} \\
\text { post-induction }\end{array}$ & $6(24 \%)$ & $13(41.9 \%)$ & $15(42.9 \%)$ & 0.268 \\
\hline $\begin{array}{l}\geq V G P R \\
\text { post-induction }\end{array}$ & $14(56 \%)$ & $26(83.9 \%)$ & $26(74.3 \%)$ & 0.064 \\
\hline $\begin{array}{l}\text { CR/nCR } \\
\text { post-ASCT }\end{array}$ & 15 (62.5\%) & $23(74.2 \%)$ & $19(63.3 \%)$ & 0.569 \\
\hline$\geq$ VGPR post-ASCT & 19 (79.2 \%) & 29 (93.5\%) & $27(90 \%)$ & 0.242 \\
\hline 5-year OS & $59.80 \%$ & $78.70 \%$ & $73.80 \%$ & 0.661 \\
\hline 5-year EFS & $36.30 \%$ & $52.50 \%$ & $69.80 \%$ & 0.516 \\
\hline
\end{tabular}




\section{Treatment results}

The post-induction $\mathrm{CR} / \mathrm{nCR}$ rate were $24 \%, 41.9 \%$ and $42.9 \%$ in patients receiving the staged approach, PAD and VTD respectively $(\mathrm{p}=0.268)$. Post-induction $\geq$ VGPR rates were $56 \%, 74.2 \%$ and $63.3 \%$ in patients receiving the staged approach, PAD and VTD respectively $(\mathrm{p}=0.064)$. While there was a trend of lower $\geq$ VGPR rate in patients receiving the staged approach compared with frontline PAD or VTD, the difference disappeared after ASCT (post-ASCT $\geq$ VGPR rate in staged approach, PAD and VTD were $79.2 \%, 93.5 \%$ and $90 \% ; \mathrm{p}=0.242$ ). Of the whole group of 91 patients, the overall $\mathrm{CR} / \mathrm{nCR}$ rate and $\geq$ VGPR rates were $37.4 \%$ and $72.5 \%$ after induction therapy, and $62.6 \%$ and $82.4 \%$ after ASCT.

\section{Prognostic indicators}

To identify potential risk factors impacting the achievement of $\mathrm{CR} / \mathrm{nCR}$ or $\geq \mathrm{VGPR}$ either post-induction or post-ASCT, parameters including regimen, isotype, ISS gender or presence of high-risk karyotype were correlated with the achievement of $\mathrm{CR} / \mathrm{nCR}$ and $\geq \mathrm{VGPR}$ post-induction and post-ASCT (Table 2). Of these factors, induction $\mathrm{CR} / \mathrm{nCR}$ rate was not impacted by regimen $(p=0.268)$, ISS $(p=0.781)$ or gender $(p=0.518)$ but impacted by isotype $(\mathrm{p}=0.017)$ with lower postinduction $\mathrm{CR} / \mathrm{nCR}$ rate in those with IgG and IgD isotype. Moreover, IgG isotype had a trend for lower $\geq$ VGPR rate post-induction. In factors analysed for achievement of post-ASCT responses, IgG isotype and male gender were associated with lower $\mathrm{CR} / \mathrm{nCR}$ rate but none of these factors correlated with the achievement of $\geq$ VGPR post-ASCT. Interestingly, neither advanced ISS (ISS III) nor high-risk karyotypes impacted on $\mathrm{CR} / \mathrm{nCR}$ rates or $\geq \mathrm{VGPR}$ rate after both induction and ASCT.

\section{Survivals}

In this combined cohort, the 5-year OS and event-free (EFS) survivals were $66 \%$ and $45.1 \%$ (median EFS: 48 months) (Figure $2 \mathrm{~A} \& 2 \mathrm{~B}$ ). There was no difference between the induction $\mathrm{CR} / \mathrm{nCR}$ rate $(\mathrm{p}=0.268)$, EFS $(0.516)$ or $\mathrm{OS}(\mathrm{p}=0.661)$ of patients induced by these three regimens (Figure $3 \mathrm{~A} \& 3 \mathrm{~B}$ ). In univariate analysis, ISS III (Figure 4A), male gender and failure of CR postASCT (Figure 5A) predicted an inferior OS (Table 3). On the other hand, ISS III (Figure 4B), failure of CR post-

Table 2 Factors impacting post-induction CR/nCR, post-induction VGPR, post-ASCT CR/nCR and post-ASCT VGPR

\begin{tabular}{|c|c|c|c|c|}
\hline & $\begin{array}{l}\text { Post-induction } \\
\text { CR/nCR (\%) }\end{array}$ & Post-induction $\geq$ VGPR (\%) & $\begin{array}{l}\text { Post-ASCT } \\
\text { CR/nCR (\%) }\end{array}$ & Post-ASCT $\geq$ VGPR (\%) \\
\hline \multicolumn{5}{|l|}{ Regimen } \\
\hline Staged approach & $6(24 \%)$ & $14(56 \%)$ & $15(62.5 \%)$ & 19 (79.2 \%) \\
\hline PAD & $13(41.9 \%)$ & $26(83.9 \%)$ & $23(74.2 \%)$ & 29 (93.5\%) \\
\hline VTD & $15(42.9 \%)$ & $26(74.3 \%)$ & 19 (63.3\%) & $27(90 \%)$ \\
\hline p-value & 0.268 & 0.064 & 0.569 & 0.242 \\
\hline \multicolumn{5}{|l|}{ Age* } \\
\hline p-value & 0.547 & 0.698 & 0.416 & 0.730 \\
\hline \multicolumn{5}{|l|}{ Gender } \\
\hline male & $17(34 \%)$ & $34(68 \%)$ & $27(57.4 \%)$ & 40 (85.1\%) \\
\hline female & $17(41.45 \%)$ & $32(78 \%)$ & $30(78.9 \%)$ & 35 (92.1\%) \\
\hline p-value & 0.518 & 0.349 & 0.04 & 0.501 \\
\hline \multicolumn{5}{|l|}{ ISS } \\
\hline 1 & $10(34.48 \%)$ & $19(65.5 \%)$ & $20(71.4 \%)$ & $26(92.9 \%)$ \\
\hline$\|$ & $8(44.44 \%)$ & $14(77.8 \%)$ & $13(72.2 \%)$ & $16(88.9 \%)$ \\
\hline III & $16(37.21 \%)$ & $33(73.3 \%)$ & $24(63.2 \%)$ & $32(84.2 \%)$ \\
\hline p-value & 0.781 & 0.513 & 0.431 & 0.559 \\
\hline \multicolumn{5}{|l|}{ Isotype } \\
\hline G & $8(20.0 \%)$ & $23(57.5 \%)$ & $18(47.4 \%)$ & 33 (86.8 \%) \\
\hline L & $14(56.0 \%)$ & $20(80 \%)$ & $18(81.8 \%)$ & 19 (86.4 \%) \\
\hline A & 7 (46.67 \%) & 13 (86.7 \%) & 11 (78.6 \%) & 13 (92.9 \%) \\
\hline$D$ & $2(28.57 \%)$ & $6(85.7 \%)$ & $6(85.7 \%)$ & $6(85.7 \%)$ \\
\hline NS & $3(75.0 \%)$ & $4(100 \%)$ & $4(100 \%)$ & $4(100 \%)$ \\
\hline$p$-value & 0.017 & 0.065 & 0.013 & 0.908 \\
\hline
\end{tabular}

*: $\mathrm{p}$-value refers to the comparison of the mean age of patients achieving or not achieving a response(CR/nCR or $\geq \mathrm{VGPR}$ ). 


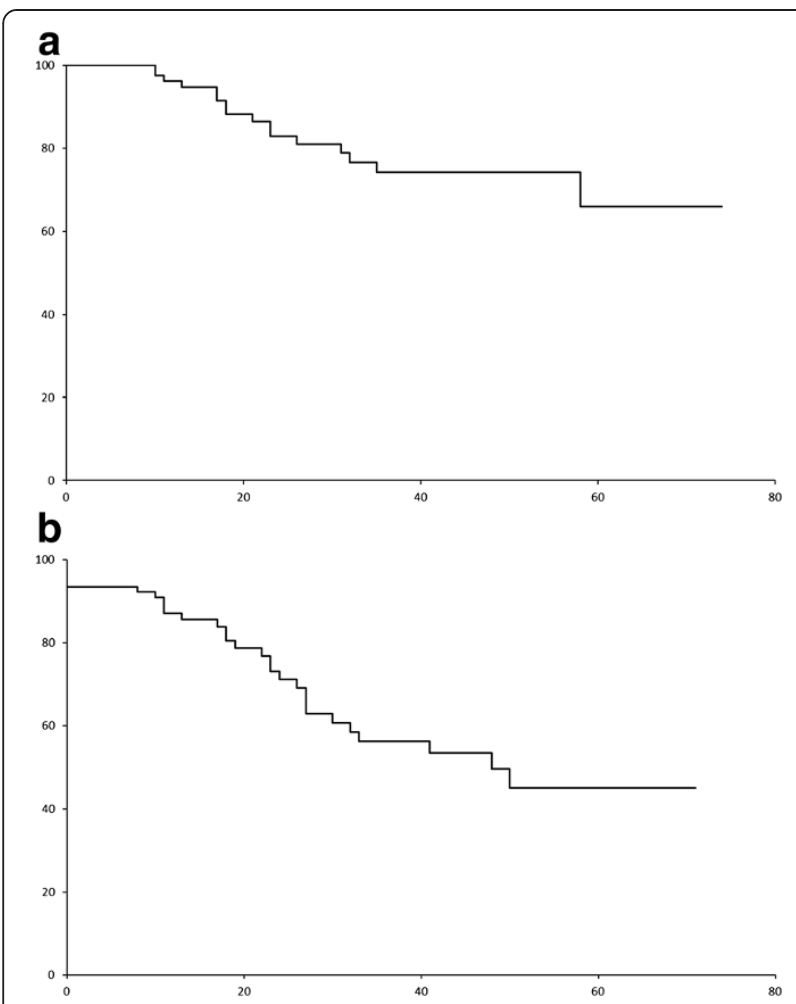

Figure 2 (A) OS of combined cohort of 91 patients; (B) EFS of combined cohort of 91 patients.



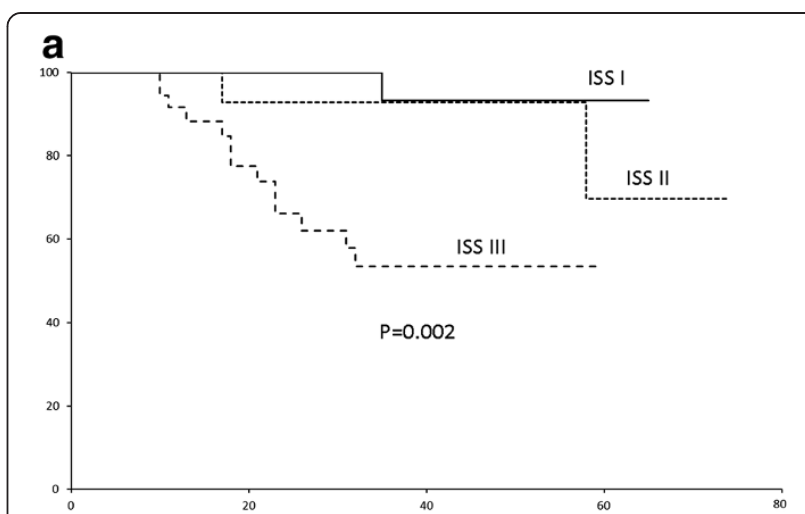

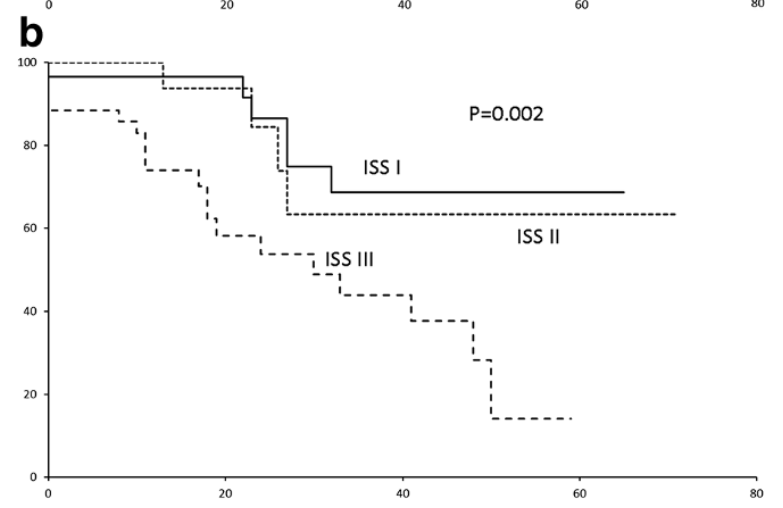

Figure 4 (A) OS by ISS; (B)EFS by ISS.

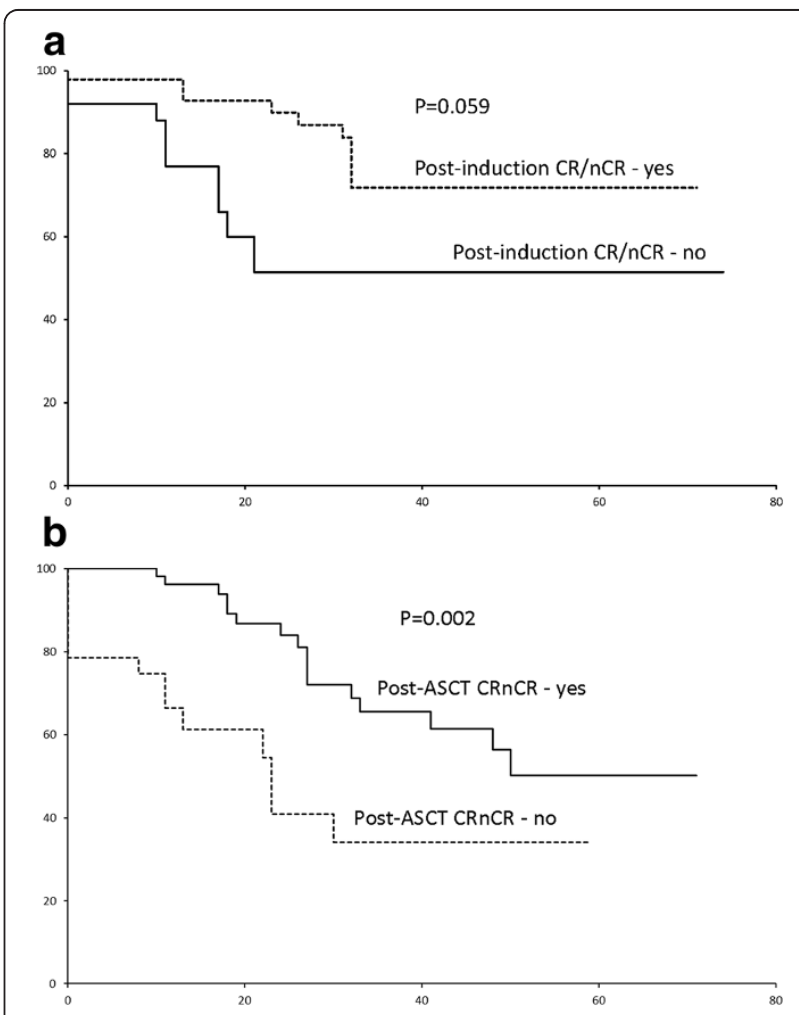

Figure 5 (A) EFS by post induction $C R / n C R$; (B) OS of post-ASCT /nCR. 
Table 3 Prognostic factors for overall survival (OS)

\begin{tabular}{|c|c|c|c|c|}
\hline & \multirow{2}{*}{$\begin{array}{l}\begin{array}{l}\text { Univariate } \\
\text { analysis }\end{array} \\
\text { p-value }\end{array}$} & \multicolumn{3}{|c|}{ Multivariate analysis } \\
\hline & & p-value & $\begin{array}{l}\text { Hazard } \\
\text { Ratio }\end{array}$ & $\begin{array}{l}\text { 95\% Confidence } \\
\text { Interval }\end{array}$ \\
\hline regimen & 0.661 & 0.320 & 0.622 & $0.245-1.584$ \\
\hline gender & 0.043 & 0.439 & 0.558 & $0.128-2.443$ \\
\hline age & 0.256 & 0.056 & 1.115 & $0.997-1.248$ \\
\hline isotype & 0.264 & 0.160 & 1.558 & $0.840-2.891$ \\
\hline ISS & 0.002 & 0.006 & 4.323 & $1.508-12.397$ \\
\hline Post-induction $\mathrm{CR} / \mathrm{nCR}$ & 0.059 & 0.291 & 0.395 & $0.070-2.216$ \\
\hline post-induction $\geq$ VGPR & 0.220 & 0.480 & 1.922 & $0.314-11.772$ \\
\hline Post-ASCT CR/nCR & 0.004 & 0.045 & 0.138 & $0.020-0.958$ \\
\hline Post-ASCT VGPR & 0.001 & 0.836 & 1.278 & $0.124-13.153$ \\
\hline
\end{tabular}

induction (Figure 5B) and failure of CR post-ASCT predicted inferior EFS. In multivariate analysis, advanced ISS and failure of post-ASCT CR/nCR predicted an inferior OS, whereas advanced ISS and failure of $\mathrm{CR} / \mathrm{nCR}$ post-induction predicted a inferior EFS (Table 4).

\section{Discussion}

There are several observations from the study. Firstly, despite this being a retrospective study, we showed that there was no difference in EFS or OS in patients receiving the staged approach and those receiving frontline PAD or VTD, suggesting that the staged approach yielded comparable survivals as patients receiving frontline bortezomib. This is encouraging because only half [14 (56\%)] of the patients receiving the staged approach required salvage VTD, and hence the staged approach could be used as a cost-effective but effective regimen in less affluent countries, where frontline bortezomib might not be affordable for the majority of the population. However, while not reaching statistical significance due to the small number of patients, it is notable that the

Table 4 Prognostic factors for event-free survival (EFS)

\begin{tabular}{lrrrrr}
\hline & $\begin{array}{c}\text { Univariate } \\
\text { analysis }\end{array}$ & & \multicolumn{3}{c}{ Multivariate analysis } \\
\cline { 2 - 3 } p-value & & p-value & $\begin{array}{c}\text { Hazard } \\
\text { Ratio }\end{array}$ & $\begin{array}{l}\text { 95 \% Confidence } \\
\text { Interval }\end{array}$ \\
\hline regimen & 0.516 & 0.751 & 0.907 & $0.495-1.661$ \\
gender & 0.061 & 0.372 & 0.640 & $0.241-1.705$ \\
age & 0.256 & 0.896 & 0.995 & $0.923-1.073$ \\
isotype & 0.237 & 0.125 & 1.339 & $0.922-1.944$ \\
ISS & 0.003 & 0.022 & 1.853 & $1.092-3.143$ \\
Post-induction CR/nCR & 0.010 & 0.041 & 0.307 & $0.099-0.953$ \\
Post-induction VGPR & 0.077 & 0.313 & 1.976 & $0.526-7.424$ \\
Post-ASCT CR/nCR & 0.002 & 0.205 & 0.439 & $0.123-1.567$ \\
Post-ACST VGPR & $<0.001$ & 0.116 & 0.275 & $0.055-1.374$ \\
\hline
\end{tabular}

$\mathrm{CR} / \mathrm{nCR}$ rate of patients receiving frontline bortezomibbased induction was much higher than that of those induced with the staged approach (42.9\% versus $24 \%$ ). Moreover, the 5-year EFS of patients receiving frontline bortezomib-based induction was almost double that of those induced with the staged approach $(69.8 \%$ versus $36.3 \%)$. Similarly, the 5-year OS of patients receiving frontline bortezomib-based induction was much higher than that of those induced with the staged approach (73.8\% versus $59.8 \%)$. Therefore, whether significant survival difference may emerge between the staged approach and PAD/VTD after prolonged follow-up remains to be seen. Interestingly, while there was a trend of lower $\geq$ VGPR rate compared to patients receiving PAD or VTD, the difference was abolished after ASCT.

Secondly, a high post-induction CR/nCR (PAD: 41.9\%; VTD: $42.9 \%$ ) and $\geq$ VGPR rates (PAD: 74.3\%; VTD: 83.9\%) were observed in patients receiving frontline PAD or VTD induction. These post-induction CR/nCR rates were comparable to other phase II studies, which also reported a high post-induction $\mathrm{CR} / \mathrm{nCR}$ rate after PAD (29\%) or CyBorD (46\%) [4,10].

Thirdly, we attempted to analyse prognostic factors impacting outcome in this combined cohort of myeloma patients receiving either frontline (PAD/VTD induction) or early bortezomib-based induction (in the staged approach). We showed that ISS III remained an important adverse risk factor predicting both inferior OS and EFS, despite patients receiving early or frontline bortezomibbased induction regimens followed by ASCT. However, there was no association between ISS III and presentation parameters including age, gender, isotype or even high-risk karyotypes. Moreover, ISS III did not result in an inferior $\mathrm{CR} / \mathrm{nCR}$ or $\geq \mathrm{VGPR}$ rate either postinduction or post-ASCT. Therefore, ISS III is a factor that predicted residual chemo-refractory disease, thereby leading to subsequent fatal relapse or disease progression. Indeed, the adverse prognostic impact of advanced ISS stage for progression-free survival has also been demonstrated in phase III studies [11,12]. Importantly, ways to improve the survivals of ISS III myeloma patients are urgently needed. In this connection, new targeted agents or next generation immunomodulatory agents are urgently required [13]. This is particularly important in this era of targeted therapy when the adverse prognostic impact of high-risk karyotypes were shown to be at least partially, if not totally, overcome by the use of bortezomib-based induction regimens. [14] The persistence of the unfavorable prognostic impact of advanced ISS despite bortezomib-based induction poses an important therapeutic challenge.

In addition, we showed that post-induction $\mathrm{CR} / \mathrm{nCR}$ predicted a superior EFS, and CR/nCR post-ASCT a superior OS. This is consistent with recent studies that 
$\mathrm{CR} / \mathrm{nCR}$ or VGPR prior to ASCT is a favorable factor predicting superior progression-free survival $[11,12,15]$, and $\mathrm{CR} / \mathrm{nCR}$ post-ACST predicts superior OS [16].

In conclusion, a high $\mathrm{CR} / \mathrm{nCR}$ and VGPR rates were achieved in patients receiving frontline or early bortezomib-based induction therapy, which was associated with favorable OS and EFS. There was no difference between the outcomes of the staged approach and frontline bortezomib-based induction regimens as PAD or VTD. ISS stage III remains an adverse prognostic factor for both EFS and OS despite frontline or early bortezomib-induction, and poses a therapeutic challenge in this era of targeted therapy when the use of bortezomib-based induction has at least partially abolished the unfavorable impact of high-risk karyotypes. $\mathrm{CR} / \mathrm{nCR}$ post-induction and post-ASCT are favorable factors predicting favorable OS and EFS, and hence are important end-points of therapy.

\section{Competing interests}

All authors report no relevant conflicts of interest.

\section{Acknowledgement}

We thank Dr Keith Stewart of Mayo Clinic, USA, and Prof Antonio Palumbo of the University of Torino, Italy for their critical review of the manuscript. Moreover, we thank Ms YY Chan and Helen So for a very efficient myeloma clinic.

\section{Author details}

'Department of Medicine, Queen Mary Hospital, University of Hong Kong, Hong Kong, Hong Kong. ${ }^{2}$ Department of Pathology, Queen Mary Hospital, University of Hong Kong, Hong Kong, Hong Kong. ' ${ }^{3}$ Department of Medicine, Pamela Youde Eastern Hospital, Hong Kong, Hong Kong. ${ }^{4}$ Department of Medicine, Tuen Mun Hospital, Hong Kong, Hong Kong. ${ }^{5}$ Department of Medicine, Princess Margaret Hospital, Hong Kong, Hong Kong. ${ }^{6}$ Department of Pathology, Hong Kong Sanatorium \& Hospital, Hong Kong, Hong Kong.

\section{Authors' contributions}

CSC, AKWL,YLK designed the clinical protocol; CSC, AKWL, HL, CSL, SFY, JS, RL, ET were involved in treating patients and collecting data; EYTC, TSW, ESKM were involved with labroatory diagnosis and FISH studies; CSC, YLK wrote the paper with contributions from the other authors. All authors read and approved the final manuscript.

Received: 10 May 2012 Accepted: 8 June 2012

Published: 8 June 2012

\section{References}

1. Richardson PG, Barlogie B, Berenson J, et al: A phase 2 study of bortezomib in relapsed, refractory myeloma. N Engl J Med 2003, 348:2609-2617.

2. Chim CS, Hwang YY, Pang C, Shek TW: Restoration of chemosensitivity by Bortezomib: implications for refractory myeloma. Nat Rev Clin Oncol 2009, 6:237-240

3. Cavo M, Rajkumar SV, Palumbo A, et al: International Myeloma Working Group consensus approach to the treatment of multiple myeloma patients who are candidates for autologous stem cell transplantation. Blood 2011, 117:6063-6073.

4. Popat $\mathrm{R}$, Oakervee HE, Hallam $\mathrm{S}$, et al: Bortezomib, doxorubicin and dexamethasone (PAD) front-line treatment of multiple myeloma: updated results after long-term follow-up. Br J Haematol 2008, 141:512-516.

5. San Miguel JF, Schlag R, Khuageva NK, et al: Bortezomib plus melphalan and prednisone for initial treatment of multiple myeloma. N Engl J Med 2008, 359:906-917.
6. Chim CS, Lie AK, Chan EY, et al: A staged approach with vincristine, adriamycin, and dexamethasone followed by bortezomib, thalidomide, and dexamethasone before autologous hematopoietic stem cell transplantation in the treatment of newly diagnosed multiple myeloma. Ann Hematol 2010, 89:1019-1027.

7. Bradwell AR, Carr-Smith HD, Mead GP, et al: Highly Sensitive, Automated Immunoassay for Immunoglobulin Free Light Chains in Serum and Urine. Clin Chem 2001, 47:673-680.

8. Bladé J, Samson D, Reece D, et al: Criteria for evaluating disease response and progression in patients with multiple myeloma treated by highdose therapy and Group for Blood and Marrow Transplant. Br J Haematol 1998, 102:1115-1123.

9. Greipp PR, San Miguel J, Durie BG, et al: International staging system for multiple myeloma. J Clin Oncol 2005, 23:3412-3420.

10. Reeder CB, Reece DE, Kukreti V, et al: Cyclophosphamide, bortezomib and dexamethasone induction for newly diagnosed multiple myeloma: high response rates in a phase II clinical trial. Leukemia 2009, 23:1337-1341.

11. Cavo M, Tacchetti P, Patriarca F, et al: GIMEMA Italian Myeloma Network. Bortezomib with thalidomide plus dexamethasone compared with thalidomide plus dexamethasone as induction therapy before, and consolidation therapy after, double autologous stem-cell transplantation in newly diagnosed multiple myeloma: a randomised phase 3 study. Lancet 2010, 376:2075-2085.

12. Moreau P, Avet-Loiseau H, Facon T, et al: Bortezomib plus dexamethasone versus reduced-dose bortezomib, thalidomide plus dexamethasone as induction treatment before autologous stem cell transplantation in newly diagnosed multiple myeloma. Blood 2011, 118:5752-5758.

13. Mitsiades CS, Davies FE, Laubach JP, et al: Future directions of nextgeneration novel therapies, combination approaches, and the development of personalized medicine in myeloma. J Clin Oncol 2011, 29:1916-1923.

14. Avet-Loiseau H, Leleu X, Roussel M, et al: Bortezomib plus dexamethasone induction improves outcome of patients with $\mathrm{t}(4 ; 14)$ myeloma but not outcome of patients with del(17p). J Clin Oncol 2010, 28:4630-4634.

15. van de Velde HJ, Liu X, Chen G, Cakana A, Deraedt W, Bayssas M: Complete response correlates with long-term survival and progressionfree survival in high-dose therapy in multiple myeloma. Haematologica 2007, 92:1399-1406

16. Lahuerta JJ, Mateos MV, Martínez-López J, et al: Influence of pre- and posttransplantation responses on outcome of patients with multiple myeloma: sequential improvement of response and achievement of complete response are associated with longer survival. J Clin Oncol 2008, 26:5775-5782

doi:10.1186/1756-8722-5-28

Cite this article as: Chim et al:: Treatment outcome and prognostic factor analysis in transplant-eligible Chinese myeloma patients receiving bortezomib-based induction regimens including the staged approach, PAD or VTD. Journal of Hematology \& Oncology 2012 5:28.

\section{Submit your next manuscript to BioMed Central and take full advantage of:}

- Convenient online submission

- Thorough peer review

- No space constraints or color figure charges

- Immediate publication on acceptance

- Inclusion in PubMed, CAS, Scopus and Google Scholar

- Research which is freely available for redistribution 